\title{
MEASURING THE NET FISCAL IMPACT OF PROJECTS IN RURAL AREAS
}

\author{
Thomas F. Cargill and Jeanne Wendel*
}

\begin{abstract}
The paper presents a simple, realistic, and cost-effective methodology for estimating net fiscal impacts that does not require input-output or structural model frameworks. The methodology is most appropriate for projects in rural areas where analytical methods are constrained by limited data. The method is illustrated in the context of additions to power capacity presented in a 1992 resource plan submitted by a power company in Nevada; however, the principles are not specific to the power company or to the state of Nevada.
\end{abstract}

\section{INTRODUCTION}

Public regulatory bodies are increasingly requiring public utilities to include analysis of regional economic impacts in the facilities planning process. Despite broad agreement that economic impacts of new power facilities can be important, considerable debate revolves around two related issues: first, what specific impacts should be measured and considered in the resource plan and second, what methodology should be used to quantify economic impacts.

The impetus to require economic impact analysis in the case of public utilities stems from the fact that power plants are often sited in rural areas, where project-related growth may exert a significant impact on the local economy. Such economic development is viewed positively by some because project-related spending increases economic activity, tax revenues, and employment. At the same time, however, additional government spending will be needed to provide services for the increasing population. The economic impact assessment should therefore address the question of whether the new facility will generate sufficient tax revenues to offset government expenditure impacts.

This issue is not unique to power plant siting; states and counties also evaluate this trade-off when considering the possibility of offering tax breaks and other subsidies to attract new commercial or industrial facilities. ${ }^{1}$

Net fiscal impact, equal to the difference between increased tax revenue and increased government expenditures, provides an estimate of the project's potential impact on local government budgets. This paper focuses on developing a

*Professor and Associate Professor of Economics, respectively, University of Nevada, Reno. The authors express appreciation to Vicki Erickson and David Poole of Sierra Pacific Power Company and Darrell Plummer of Sierra Pacific Resources for assistance in preparing this paper; however, all errors remain with the authors. 
reasonable and cost-effective methodology for estimating net fiscal impact. The methodology outlined in this paper has been successfully applied to analyze the impacts of two types of projects in the state of Nevada. First, the method was used to estimate economic impacts of a number of proposed additions to power capacity in a 1992 resource plan presented by Sierra Pacific Power Company (Sierra Pacific Power Company 1992) before the Nevada Public Service Commission. Second, the method was used to estimate economic impacts of a proposed steel processing facility in a rural Nevada county being considered as a candidate for government tax and other subsidies. ${ }^{2}$

The method does not involve new developments in regional analysis nor is it unique to power plants, the steel processing facility, or Nevada. It can easily be extended to analyze the economic impact of any new facility. The method is particularly relevant for rural areas where detailed input-output models based on local data are often unavailable.

Because net fiscal impact is to be estimated for projects in the preliminary planning phase, it is appropriate to use a relatively simple and inexpensive approach to develop rough order-of-magnitude estimates. Input-output analysis is not appropriate for estimating the impact of increased employment and population on government expenditures for two reasons. First, with reference to rural locations, input-output models tend to be based on statewide data, rather than on data specific to the rural county. Second and more general, fixed coefficient input-output models provide estimates of the average impact of employment on govemment revenue, whereas regression analysis provides estimates of marginal effects. For services with high fixed costs, the difference between average and marginal impacts can be substantial. If sufficient capacity exists to provide additional government services without new capital construction, the marginal impact is the appropriate measure of the power generation facility's impact on local govemment spending. If additional capital construction is required to provide the additional government services, this must be evaluated separately. Assessment of the need for additional capital construction requires information about the relationships between capacity and current utilization; historical data such as the data underlying input-output analysis is inadequate and inappropriate.

This paper outlines a regression-based methodology that is (1) simpler and more cost effective than the elaborate input-output or structural model approaches frequently marketed by consulting firms, (2) rooted in data on local conditions, and (3) designed to yield estimates of marginal govemment expenditure impacts. The method, however, includes use of input-output multipliers to estimate projectrelated increases in employment since the difference between marginal and average impacts is not an important issue for employment impacts. 
The remainder of the paper consists of four sections. Sections III and IV discuss the approach to measuring tax and expenditure impacts, respectively. Section $\mathrm{V}$ illustrates the application of the methodology to a recent project considered in Nevada in the 1992 Sierra Pacific Power Company resource plan. This example is selected rather than the steel processing project since the utility report is in the public domain. ${ }^{3}$ A short concluding section ends the paper.

\section{NET FISCAL IMPACT}

The net fiscal impact measure focuses on county, state, and school district general fund revenues and expenditures. Revenue impacts include both direct taxes and fees paid by the power company for the project under analysis and indirect taxes paid by project-related employees. Government expenditure impacts are estimated by analyzing the historic relationship between employment and general fund expenditures.

\section{TAX IMPACTS}

Direct taxes and fees paid by the project may include: sales tax, use tax, property tax, business license fees and taxes, unemployment and worker's compensation, building permits and special assessments, and the state portion of gasoline and diesel fuel taxes. Revenue from the first four taxes is allocated to state and county general fund and school district budgets; hence these taxes are used to estimate the project's net fiscal impact. In contrast, revenue from the remaining taxes is earmarked for programs funded by specific taxes such as building inspections funded by permit fees. Increased revenue from these taxes and fees is not included in the net fiscal impact measure because it is theoretically matched by increased government expenditures to provide additional project-related services. Data on direct tax impacts can be obtained from preliminary budget information specific to the project, although these estimates may have wide confidence intervals in the preliminary planning phase.

Indirect tax impacts include property and sales tax revenue increases attributed to project-related (direct and indirect) employment increases. These impacts can be approximated from income multipliers, measured relationships between income and taxes, household ownership data, and property tax information. For capital-intensive projects such as power generation facilities, indirect tax impacts are small relative to the direct tax impacts. 
Net fiscal impacts are estimated separately for the initial project construction and for 20 years of project operation. Care must be taken in interpreting the significance of the two types of impacts, however. While project construction often requires more employees than project operation, the construction employees may have less impact on the county budget than operations employees. Particularly on shorter projects, the families of the construction employees may be less likely to move into the county than families of the operations employees. Similariy, county capital construction projects are less likely in response to a temporary influx of people than for a more permanent population increase. Hence, the construction phase impact estimates should be viewed as upper bounds on the potential impacts, since the estimation methodology does not attempt to account for the expectation that a smaller proportion of families will move to the area for short-term construction employment than for operations employment.

\section{EXPENDITURE IMPACTS}

The expenditure impacts of a rural project are estimated in three steps: first, the historical relationship between employment impacts and government expenditures is estimated; second, the historical relationship is then used to estimate project impacts on county and state general fund expenditures; and third, impacts on school district expenditures are estimated.

Estimating the relation between employment and government expenditures. Regression analysis is used to estimate the effect of changes in employment on government expenditures. This analysis focuses on the change in variable-cost expenditures expected to result from additional employment. Available data do not provide a sufficient foundation for estimating a structural model to fully specify the complex relationships between employment, population, and county general fund expenditures. Because simple models are employed, several specifications are considered. No solid criteria are available, however, to identify which of these models specifies the employment-expenditure relationship most accurately. Estimates of the employment-govemment expenditure relationship are therefore compared from several alternative models to determine whether these relationships are sensitive to model specification. Taken together, the models identify a reasonable range of estimates for the impact of employment on government expenditures.

All regression models included in this study have county or state general fund expenditures as the dependent variable. These variables are obtained from the annual reports filed by each county with the State of Nevada Department of Taxation. Since employment is the primary independent variable of interest, two 
alternative approaches are used to measure employment based on data provided by the State of Nevada Employment Security Department. The first variable is industrial employment obtained from the Nevada Industrial Employment Summary. This data is based on unemployment compensation records and provides estimates of the number of people employed in each county, without regard to each worker's county of residence. The second variable is based on information published in the Labor Force Summary, which reports the results of a monthly survey on labor force participation and unemployment. The difference between the number of people estimated to be in the labor force and the number estimated to be unemployed yields an estimate of the number of county residents who are employed. The first approach for estimating employment, based on place of work, is more relevant for impact analysis; however, the second approach, based on place of residence, was also utilized to evaluate whether the analysis is sensitive to the type of data used.

Clearly, individual county characteristics may affect county general fund expenditures in addition to the impacts of population and employment or unemployment. Unfortunately, the fact that county expenditure data is only available annually limits the number of observations that can be included in the regression analysis, without covering a time period that includes significant structural changes. The limited sample size makes it unlikely that reliable government expenditure-employment relationships can be estimated individually for each county. At an early stage of the project, the government-expenditure employment relationship was estimated for individual counties; however, the results varied widely from county to county and would have provided an unreliable statistical base for assessing economic impacts from expanded employment. Instead, the relationship was estimated for two partitions of the time series of cross sections (observations from 1980 to 1991 for Nevada's 17 counties): 15 rural counties and 2 urban counties (Clark and Washoe). This partition is based on the obvious differences between rural and urban regions within Nevada.

Generalized Least Squares (GLS) estimation is used to accommodate the pooled cross-section/time series data. The following four models were estimated for each of the two data sets (rural counties and urban counties):

Dependent Variable

Government expenditures

Government expenditures

Government expenditures

Government expenditures
Independent Variables

Employment (Emp)

Employment, unemployment rate

(Emp-Unemp)

Industrial employment (IndEmp)

Industrial employment, unemployment rate (IndEmp-Unemp) 
The regression equations are estimated using the natural logarithms of each observation; hence the estimated coefficients represent elasticities. The estimated impacts are summarized in Table 1. All regression coefficients are significant at the 5 percent level. The following points summarize the regression analysis findings:

\section{TABLE 1 \\ Regression Results \\ Estimated Elasticity of County General Fund \\ Expenditures with Respect to Employment \\ in 17 Counties from 1980 to 1991}

\begin{tabular}{|c|c|c|c|c|c|}
\hline & Model & & $\begin{array}{c}\text { Rural Counties } \\
\text { Employment } \\
\mathrm{R}^{2} \text { Elasticity } \\
\end{array}$ & & $\begin{array}{c}\text { Urban Counties } \\
\text { Employment } \\
\mathbf{R}^{2} \text { Elasticity }\end{array}$ \\
\hline 1. & Emp & .61 & $\begin{array}{c}.73 \\
(t=16.7)\end{array}$ & .68 & $\begin{array}{c}.99 \\
(t=6.9)\end{array}$ \\
\hline 2. & Emp-Unemp & .62 & $\begin{array}{c}.70 \\
(t=15.5)\end{array}$ & .82 & $\begin{array}{c}1.08 \\
(t=9.6)\end{array}$ \\
\hline 3. & IndEmp & .69 & $\begin{array}{c}.66 \\
(t=19.7)\end{array}$ & .71 & $\begin{array}{c}1.05 \\
(t=7.3)\end{array}$ \\
\hline 4. & IndEmp-Unemp & .69 & $\begin{array}{c}.65 \\
(t=18.0)\end{array}$ & .82 & $\begin{array}{c}1.09 \\
(t=9.7)\end{array}$ \\
\hline
\end{tabular}

Number of observations for rural counties $=180$.

Number of observations for urban counties $=30$.

1. Estimated employment elasticity is not systematically sensitive to inclusion of the unemployment rate in the equation.

2. The estimates using industrial employment (place of work) to measure employment are not significantly different from the estimates using employment (place of residence); hence the choice between the two measures of employment is not critical. Industrial employment (place of work) is preferred since it corresponds conceptually to project employment impacts.

3. The estimated coefficients are higher for urban counties than for rural counties. The statistical significance of these differences was tested by estimating additional regression equations using all counties, both rural and urban. These regressions included the variables listed for models 14 plus two additional variables: an urban/rural dummy variable and an interactive term equal to the product of the dummy variable and employment. Both the dummy variable and the interactive term were significant in all regressions with t-statistics greater than 2.5 in absolute 
value. The urban-rural location distinction is important; therefore, rural and urban elasticities should be estimated separately.

Smaller elasticities for rural areas are expected for the state of Nevada for two reasons. First, urban and rural employment patterns differ significantly. A larger portion of Nevada's urban work force is involved in tourist-related activities. Increased employment in tourist-related firms is accompanied by increased numbers of tourists, who place additional demands on government budgets. Second, many of Nevada's rural counties are sparsely populated. In areas with low population densities, distance increases the cost of providing some government services such as road maintenance, school transportation, or services that may require maintaining an office even though the population base is insufficient to fully utilize the capacity. This impact of distance on service costs may make govemment expenditures less sensitive to population changes in low-density rural areas than in urban areas.

4. The high estimates (.73 for rural counties and 1.09 for urban counties) were used in the application presented in this paper to avoid underestimating the expenditures triggered by employment impacts. In contrast, for a project being considered for tax subsidies, low estimates would be appropriate for generating conservative net fiscal impacts.

Impact on county and state general fund expenditures. The elasticity estimates represent the percentage change in government expenditures that are expected to result from a 1 percent change in employment. This is the central relationship needed to estimate the impact of additional employment on govemment expenditures. Several additional steps are required to calculate estimates. First, the increase in employment must be converted into a percentage change. Since the increased employment is expected to persist over a multi-year planning horizon, this will require county employment projections. Second, after the elasticity estimate is combined with each annual percentage change in employment to yield annual percentage changes in government expenditure, these percentage changes must be converted into dollar values. Finally, the annual estimates must be adjusted for inflation, discounted, and summed to calculate the present value of expenditure impacts.

To estimate the dollar value of government expenditure changes, it is necessary to first calculate the projected change in employment as a percent of projected county employment. Projected county employment is estimated by regressing employment against a time trend variable. This model yields reasonably good fits $\left(\mathbf{R}^{2}\right.$ measures above .95$)$ and provides estimates of long-term employment growth rates for each county. These growth rates are used to project 
1992 employment in each county, which is then used as the base for calculating the percentage change for the annual employment changes in both the construction and operation phases. This approach yields relatively high values for percentage changes in employment, since the base used to calculate the percentage change does not continue to grow over time. Projecting individual county employment beyond 1992 may introduce errors into the analysis; however, more sophisticated employment projections could easily be incorporated. In general, rural county data bases are insufficient to generate reliable employment projections beyond a few years at the most.

The product of the multiplier and the percentage change in employment yields the percentage change in government expenditures expected for each project. The product of this percentage change and projected 1992 government expenditures yield the dollar value of the change in government expenditures expected for each project. For example, consider a project that would employ 100 people in a rural county. Suppose regional data indicate an employment multiplier of 2.0, so that project-related employment is estimated at 200. Suppose, further, that current county employment is 20,000 , so this project will increase employment by 1 percent. Since the estimated elasticity, [\% change govt expenditure]/[\% change employment] $=.73$, project-related employment will then induce a .73 percent increase in county general fund expenditures. If the county general fund expenditure is projected to be $\$ 10,000,000$ in a given year, the project's government expenditure impact is estimated to be $\$ 73,000$ for that year.

Since the expenditure impacts occur over periods of many years, the estimated annual impacts are adjusted for inflation and then discounted to calculate the present values of construction and operation impacts. The impact present values are stated in 1992 dollars.

An analogous process will yield estimates of the project's impacts on state general fund expenditures.

Impact on school district expenditures. The impact on school district expenditures is estimated with a different procedure because the State Distributive School Account total guarantee plays an important role in local school district funding. The State Distributive School Account funds 42 percent of local school district budgets, while local property and sales taxes fund 54 percent of these budgets. The state total guarantee plays a larger role than is suggested by these figures, however, because the guarantee formula is used to determine a total funding level. Local property and sales tax revenues are subtracted from this amount to determine the amount to be paid from the State Distributive School Account to the local school district. The formula multiplies a dollar amount per student times the number of students enrolled in the district to determine the total guarantee. The dollar amount per student is adjusted to reflect local district conditions such 
as income levels and transportation requirements. Since school district budgets are heavily dependent on a calculated dollar amount per student and the number of students enrolled, we use the average spending per student to estimate the effect of employment on school district expenditures.

Estimation of the impact of additional employment on school expenditures requires an estimate of the impact on school enrollment. This impact is estimated in two steps. First, the impact of employment on population is estimated separately for urban and rural counties with a GLS regression of population on industrial employment. The regression is estimated for all counties, with the 12-year data set. The regression is estimated using raw data (without taking natural logs) so the estimated coefficient represents the change in population that corresponds to one additional job. The estimated coefficient is robust with respect to the choice of employment or industrial employment and with respect to the inclusion or exclusion of the unemployment rate. Second, the estimated population increase associated with each additional job is combined with data on school enrollment per capita and school district expenditure per student to calculate school district spending per employee.

\section{v. CASE STUDY}

The 1992 Sierra Pacific Power Company resource plan identifies eight "generic" projects that are characterized by fuel type, megawatt capacity, percent baseload versus peaking capacity, and county. The county is a relevant identifying characteristic because the project employment and expenditures as percentages of total county employment and general fund expenditures are important determinants of the project's impact. Consistent with the plan's preliminary status, specific locations within each county are not identified in the plan. The projects include geothermal, combustion turbine, and coal-fired generation facilities ranging from 12-40 megawatts for the geothermal plants to 300 megawatts for the largest coal project.

Table 2 presents the results of applying the above method to a 300 megawatt coal-fired power generation facility proposed for construction in Humboldt County. Humboldt is a rural county with 1991 employment equal to 6,628 out of a population of 13,510. The county's 1991 general fund expenditure was $\$ 5.3$ million. Peak project-related employment represents 17 percent of county employment during the construction phase and 1 percent during the operations phase. Despite the magnitude of expected coal shipments, public transportation infrastructure is not a major issue since the coal will be transported by rail using ex- 
TABLE 2

Net Fiscal Impacts: Power Plant

Project type:

Location:

Size:

Maximum employment

Construction phase:

Operation phase:

Base load factor.
Coal

Humboldt County, NV

300 megawatts

746

57

80 percent

PV PV/MW Annualized cost/MWH (base load)

(1000's of 1992 \$) 1992 \$

Construction Phase:

3 years

Government revenue impacts

Sales, use, property taxes*

Direct, paid by firm

31,393

1,933

Indirect, paid by individuals

Total revenue impact

Government expenditure impacts

County general fund

33,326

105
6
111
6
14
30
50

State general fund

Total expenditure impact

1,915

4,145

9,057

15,117

60

Net Fiscal Impact

18,208

Operation Phase:

20 years

Government revenue impacts

Sales, use, property taxes*

Direct, paid by firm

Indirect, paid by individuals

Total revenue impact

108,698

362

8.31

109,233

364

Government expenditure impact

County general fund

458

$2 \quad 0.04$

School district

992

0.08

State general fund

Total expenditure impact

2,168

3,619

0.16

$105,614 \quad 352$

0.28

Net fiscal impact

8.07

*The category labeled "Sales, use, property tax" also includes payments for Nevada's business tax.

isting lines. An inflation rate of 4.1 percent and a discount rate of 10.3 percent were assumed throughout the analysis.

To facilitate comparison of the economic impacts of a broad range of projects with diverse scales, levels of capital intensity, and construction lead times, the net fiscal impact is reported in three formats: net present value, impact 
per megawatt, and annualized impact (where the annualized impact is the annual payment of an annuity with a present value equal to the project's fiscal impact present value).

Net fiscal impacts are estimated for the construction and operations phases of the project. The present value of sales, use, and property taxes to be paid by the firm are calculated from Sierra Pacific Power Company's estimated construction and operations budgets. Multipliers are not applied to these numbers directly because most of these tax payments will be property taxes. (The project's largest expense will be coal, which is not purchased locally.) Project payments for wages and salaries will generate additional local economic activity, which will generate indirect tax payments.

Indirect tax payments include sales and property tax payments made by project-related employees. Sales tax payments by project-related employees are estimated by (1) calculating total (direct and indirect) income using the appropriate income multiplier from the IMPLAN model and (2) assuming that onethird of gross wages are spent on taxable items in Nevada. Sales tax payments are estimated for both construction and operations employees. Property tax payments, in contrast, are estimated for operations employees only. (With a construction period of three years, it is unreasonable to assume that new construction will be undertaken to house the employees.) An upper bound estimate of property tax payments is calculated by assuming that two-thirds of the direct and indirect employees will purchase houses (or property) valued at $\$ 130,000$. Property tax payments are 3 percent of 35 percent of this assessed value.

Net fiscal impact is equal to the difference between increased tax payments and increased government general fund expenditures. Estimates of the project's impact on general fund expenditures are derived from the regression-based methodology described above. These estimates should be interpreted as order-ofmagnitude estimates that provide a preliminary screen to indicate whether a proposed project may impose fiscal strains or confer fiscal windfalls on state and local government entities. For the operations phase of the project described here, the present value of government revenue impacts overwhelm the present value of the expenditure impacts. If the two estimates were closer, sensitivity analysis would be appropriate to interpret the results of this type of analysis.

\section{CONCLUDING COMMENTS}

Public utility resource planning requires consideration of many potential projects, and, at the same time, utilities are increasingly being required to assess various economic impacts associated with each proposed project. Similarly, states 
and counties are frequently pressured to evaluate economic development strategies and tax incentive policies designed to attract new industrial construction.

Net fiscal impact of these projects is clearly a fundamental measure of concern to policymakers. The method for measuring net fiscal impact outlined in this paper offers advantages over the more traditional input-output approaches frequently used for measuring project impacts, especially for projects located in rural areas. The approach presented here has four advantages: (1) it focuses on marginal rather than average effects, thus separating the analysis of operating and capital expenditure impacts; (2) the underlying data are rooted in local conditions; (3) it can be implemented at reasonable cost; and (4) the regression-based approach is simple and therefore appropriate for preliminary planning. While not to deny the usefulness of more elaborate modeling approaches in the context of an adequate data base, the proposed method provides meaningful measures of net fiscal impact in the presence of limited data availability characteristic of projects in rural areas.

The method provides rough order-of-magnitude estimates of net fiscal impact that can be applied to numerous projects in the preliminary planning stage. In the case of public utilities, the utility would want to rank projects according to net fiscal impact to determine which projects pay themselves in terms of their impact on the government budget and which projects might impose net costs on govemment budgets. Once the choice is narrowed to a small number of projects, more detailed, location-specific analyses would be required. In the case of projects being considered for tax subsidization, the net fiscal impact measure would be important for evaluating tax subsidy proposals.

\section{ENDNOTES}

1. Herzog and Schlottmann (1991) provide a broad perspective on related industrial location and economic development issues including both conceptual discussions and empirical evidence.

2. This study was completed in late 1992 at the request of Sierra Pacific Resources. The report, however, is not in the public domain.

3. The example presented in this paper incorporates a more detailed analysis of taxes than the one presented in the 1992 report (Sierra Pacific Power Company 1992) resulting in small differences in measures of net fiscal impact.

4. Swallow and Johnson (1987) present a model of government expenditures on six service categories: public safety, parks/recreation, health/welfare, courts, administration, and public works. This approach is not appropriate for the current 
application because the lack of independence among the amounts spent in each category makes aggregation of the detailed estimates problematic.

5. IMPLAN was developed by the U.S. Department of Agriculture's Forest Service to estimate the economic impacts of proposed changes in land and resource management practices. IMPLAN combines national, state, and countylevel data to model state and county economic relationships. The model was initially developed with 1982 county-level data and has been updated using 1987 price data. The analysis summarized in Table 2 included the following IMPLAN multipliers: employment, household wages, state and local government, manufactured goods, and income.

6. Census data for $\mathbf{1 9 8 0}$ show that approximately two-thirds of households live in owner-occupied dwellings in rural Nevada. This assumption is reasonable for counties with low vacancy rates. In a state such as Nevada where rural county employment is sensitive to metals pricing, project timing is an important factor in determining actual impacts.

\section{REFERENCES}

Agricultural Experiment Station. "Financing New Mexico Local Government." New Mexico State University Bulletin 704.

Brucker, S. M., S. E. Hastings, and W. R. Latham. "Regional Input-Output Analysis: A Comparison of Five 'Ready-Made' Model Systems." Review of Regional Studies 17, no. 2 (Spring 1987): 1-16.

Herzog, H. W., and A. M. Schlottmann. Industry Location and Public Policy. Knoxville: University of Tennessee Press, 1991.

Nevada Public Service Commission, General Order 65 (Based on Senate Bill 497, 1988), 1991.

Sierra Pacific Power Company. Electric Resource Plan 1992-2011 Supply Side Plan, Environmental \& Economic Externalities \& Financial Analysis. Reno, Nevada, July 1992.

Swallow, B. M., and T. G. Johnson. "A Fiscal Impact Model for Virginia Counties." Review of Regional Studies 17, no. 2 (Spring 1987): 67-74.

Trisko, E. M. "Environmental Externalities: Thinking Globally, Taxing Locally." Unpublished manuscript. 